\title{
Locked Down unto the Screens: advertisements during kids' movies in COVID -19 era
}

\section{LCD Peiris, AG Jayasinghe*, BJSL Jayathunga, KGR Mewantha Thelis, PSK Monarawila}

Faculty of Medicine, University of Kelaniya, Sri Lanka

*Correspondence: jamanda1210@gmail.com

(iDhttps://orcid.org/0000-0002-8151-4243

DOI: https://doi.org/10.4038/jccpsl.v26i4.8402

Received on 30 December 2020

Accepted on 31 December 2020

The inexperienced unguarded mind of the child has quite ingeniously been targeted by numerous commercial advertisements, telecasted especially during peak viewing hours of children. This is amidst a positive correlation that had been proven between targeted advertisements for kids and incidence of health issues in young children.

With the emergence of COVID-19, at the initial stages of lockdowns and movement restrictions, many were able to enjoy quality time with their families. However, as the new normal got 'normalized', most individuals returned to their day-to-day routines. Children, neither being able to play outside with their friends nor attend school to carry on with their studies as usual, had more time on their hands to watch television. Within the context of parents assuming "kids' movies" are safe to watch and with television channels telecasting 'kids' movies" on almost all days of the week, as anticipated, a considerable rise in the total television usage of children has occurred since the beginning of the pandemic.

We, a group of undergraduates of the Faculty of Medicine, University of Kelaniya, investigated the advertisements telecasted during a week in the month of December in every local channel during the kids'

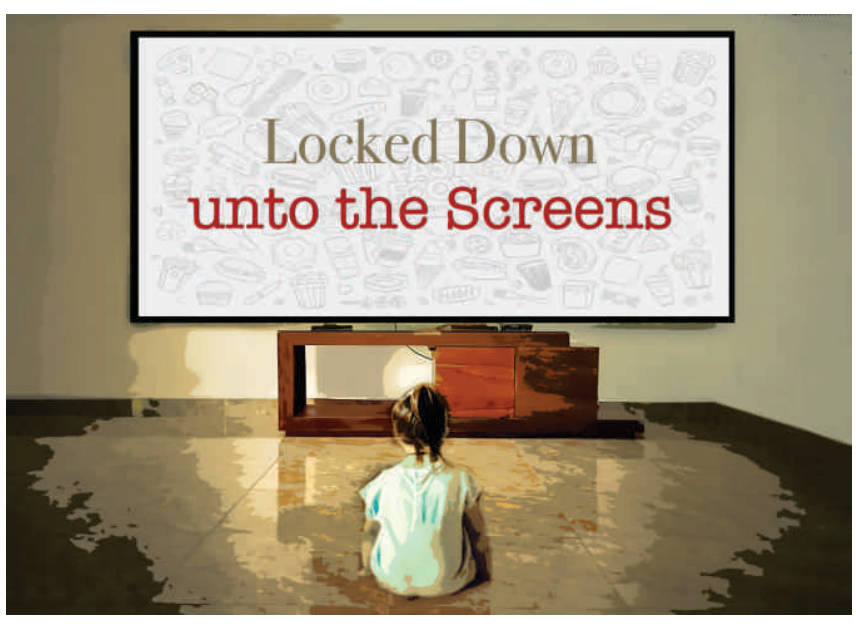
movies. Of the innumerable array of products being commercialized, food items are seen to dominate the arena. In the backdrop of rising childhood obesity levels across the globe, food marketing to children has been recognized as one of its main contributory factors. Not only these advertisers have inevitably succeeded in using tactful strategies to talk their viewers in to trusting the claims they make about their products, but also convince the younger generations to change their food habits. The food being advertised are mostly high-sugar, ultra-processed - quite further from the food items originally found in the Sri Lankan culture, and low in nutritional value.

We also noted that there is a considerable number of products which, despite not having a consumer base of children, are still being advertised during their peak viewing hours. Beauty products that include skin whitening 
creams and tablets taken to slim down body are to name a few, which questions the appropriateness of exposing naïve minds to unverified solutions, and beyond that, most importantly the role TV commercials play in inculcating discriminative ideas about skin colour and body image.

Furthermore, certain approaches used to advertise, such as promotion of certain behaviours and instilling notions about modern trends, have potential long term adverse effects on children, especially by guiding their "choices". Many false claims made are persuasive up to an extent of reducing the tendency to look into their scientific basis or even doubt the actual facts. When commercials present a group of trendsetters of a high school gulping down carbonated drinks or a celebrated personality promoting instant noodles, the above arguments become coherent to one who is vigilant about how multinational companies target kids to change habits and cultures of a population to increase their profits.

Previous studies have proposed regulating food marketing as an important preventive step against health issues such as childhood obesity, and therefore the development of such statutory regulations to delimit unhealthy food advertising during peak viewing hours of children could be a useful primary preventive measure to safeguard child health in Sri Lanka. Proper legal authorities and systems such as the Advertising Standards Authority in UK, should be established for monitoring the advertisements and take action in policy violations. Increasing awareness among parents to accompany their children when viewing programs should also be emphasized on, coupled with improving their competence in identifying and contradicting the negative messages delivered to kids via the TV in their own living rooms.

\section{References}

1. Kelly B, Halford J, Boyland E, Chapman K, Bautista-Castano I. Television food advertising to children: a global perspective. American Journal of Public Health 2010; 100(9): 1730-1736.

2. Rathod R \& Parmar B. Impact of television advertisements on children: an empirical study with reference to chocolate brands. Pacific Business Review International 2012; 5: 85-94.
3. Warren R, Wicks R, Wicks J, Fosu I, Chung D. Food and beverage advertising on U.S. television: a comparison of child-targeted versus general audience commercials. Journal of Broadcasting \& Electronic Media 2008; 52(2): 231-246.

4. UNICEF. Rethinking screen-time in the time of COVID-19, 2020. Available from: https://www. unicef.org/globalinsight/stories/rethinking-screentime-time-covid-19. 